\title{
Vertical jump development in elite adolescent volleyball players: Effects of sex and age
}

\author{
Mája Polakovičová1,2,*, Miroslav Vavák ${ }^{1}$, Róbert Ollé ${ }^{1}$, Michal Lehnert ${ }^{3}$, and Martin Sigmund ${ }^{3}$ \\ ${ }^{I}$ Faculty of Physical Education and Sports, Comenius University in Bratislava, Bratislava, Slovakia, ${ }^{2}$ Faculty of Pharmacy, \\ Comenius University in Bratislava, Bratislava, Slovakia; and ${ }^{3}$ Faculty of Physical Culture, Palacký University Olomouc, \\ Olomouc, Czech Republic
}

Copyright: (C) 2018 M. Polakovičová et al. This is an open access article licensed under the Creative Commons Attribution License (http://creativecommons.org/licenses/by/4.0/).

\begin{abstract}
Background: Vertical jump is one of the most prevalent activities performed in volleyball. During adolescence, boys and girls undergo substantial changes in physiological and anthropometric characteristics that influence vertical jump performance. Objective: The purpose of this study was to examine and quantify sex and age-related differences in vertical jump performance assessed as vertical jumps height $(\mathrm{VJH})$ and ground contact time $\left(\mathrm{T}_{\mathrm{c}}\right)$ during repeated vertical jump tests within the Czech and Slovak population of elite adolescent volleyball players. Further aims were to compare the obtained results to non-athletic adolescent national normative data and investigate the relationship between basic anthropometric measures and VJH. Methods: The cross-sectional study was conducted on 203 females and 180 males from 13 to 19 years old. Statistical analysis of VJH differences between sex and age categories was performed using two-way ANOVA with Tukey's post hoc test. The relationship between basic anthropometric parameters and VJH were examined by Pearson's correlation analysis. Results: ANOVA showed statistically significant differences in VJH between males and females $(p<.001)$ and across the age categories $(p<.001)$. Males performed better than females in each age group and VJH increased along with age. For females VJH reached a plateau at the age of 14 and then stagnated. Male players have lower $T_{c}$ than females $(p<.05)$, although age did not show significant influence on $\mathrm{T}_{c}$ in either females or males $(p>.05)$. Volleyball players have significantly higher VJH than nonathletes across all age categories and sex differences in volleyball players were smaller than the sex differences among non-athletic adolescents. A correlation analysis revealed only weak sex specific correlations of VJH with body height, body mass and BMI. Conclusions: The presented study showed significant sex differences in VJH between elite male and female volleyball players from the age of 15 . VJH increases continually with increasing age in males. In females the effect of age on VJH was insignificant.
\end{abstract}

Keywords: volleyball, vertical jump height, ground contact time, adolescents, anthropometry

\section{Introduction}

Volleyball is a high-intensity team sport based on short and frequent explosive activities such as jumping, diving, and ball play (Sheppard, Nolan, \& Newton, 2012). Besides the technical and tactical skills, well-developed speed, agility, and muscular power are required for high-level volleyball performance (Nikolaidis, Ziv, Arnon, \& Lidor, 2012; Sheppard, Gabbett, \& Stanganelli, 2009). Regarding anthropometric profiles, great height, lean body mass, and low-fat percentage seem to

\footnotetext{
* Address for correspondence: Mája Polakovičová, Hamar Institute for Human Performance, Faculty of Physical Education and Sports, Comenius University in Bratislava, Nábr. arm. gen. L. Svobodu 9, 81469 Bratislava, Slovakia. E-mail: maja.polakovicova@uniba.sk
}

be prerequisites of high-level volleyball players (Nikolaidis, Afonso, \& Busko, 2015). Several studies have related optimized performance in volleyball to a welldeveloped and durable jumping ability (Sattler, Hadžić, Dervišević, \& Markovic, 2015; Sheppard et al., 2009). Players with strong vertical jump performance are able to get higher above the net for spiking and scoring as well as in defensive play for blocking. Jumping can also influence serving by producing more dynamic hits and power (Matušov, Zapletalová, Duchoslav, \& Hagara, 2013). Therefore, vertical jump ability belongs to the elements that strength and conditioning programs aim to improve (Lehnert et al., 2012). Vertical jump involves a highly coordinated sequence of events comprising nearly all neuro-muscular parts of lower extremities, whereupon many factors such as jumping 
technique, balance, muscular power production, and anthropometric characteristics are proven to contribute to the performance in vertical jump (Sheppard et al., 2008).

Besides the physiological and anthropometrical factors, sex and age also play a significant role in the vertical jump (Doré et al., 2005). During adolescence, marked changes in human physiology occur due to muscular, neuronal and hormonal factors (Roemmich $\&$ Rogol, 1995). With puberty, males usually become larger in skeletal length, width and in muscle size, but smaller in relative fat mass compared to females (Seger \& Thorstensson, 2000). However, the observed jumping performance progress remains problematic to assess since the concurrent contribution of anthropometric changes in biological maturation and physical exercise during growth in boys and girls (Martin et al., 2004). Normative data for English school children aged 10-15 years have shown that jump height increases significantly year on year for boys. For girls, jump height reaches a plateau after the age of 12 (Taylor, Cohen, Voss, \& Sandercock, 2010). Sex specific normative paediatric data in Caucasian children and adolescents aged 6-19 years have presented that both maximum peak power and maximum force of jumping were strongly dependent on age and weight in both sexes. Both parameters steadily increased in boys and plateaued in girls aged $>13$ years (Sumnik et al., 2013). A physical fitness population study of European adolescents revealed normative data for a battery of 10 fitness tests including squat jumps, counter movement jumps and Abalakov jumps with the same trend regarding the sex and age (Ortega et al., 2011).

All of the above mentioned studies reported normative data of the non-athletic population which suggests that they are apparently not influenced by regular sport training. Many of the changes associated with regular training, although not all, go in the same direction as those that follow normal growth and maturation. It is difficult to partition training effects from those of normal growth and maturation in the available data (Naughton, Farpour-Lambert, Carlson, Bradney, \& Van Praagh, 2000). Studies monitoring sex and age specific development in the motor abilities in the athletic adolescent population are less reported. Shortterm longitudinal studies of male and female athletes in a variety of sports indicate growth rates within the range expected for non-athletes (Malina, 1998). Progression differences as a function of age and sex were identified in running and jumping events in Norwegian adolescent track and field athletes. The study highlighted that performance improvement during puberty is considerable depending on the sport discipline (Gallová, Doležajová, Lednický, Matulaitis, \& Bračič, 2015;
Tonnessen, Svendsen, Olsen, Guttormsen, \& Haugen, 2015). Therefore, the main purpose of our research was to investigate the effect of sex and age on vertical jump development in elite adolescent volleyball players. In many sports like volleyball and basketball, a jump needs to be high enough but also not take too long to execute, otherwise the opportunity to intercept the ball may be missed (Domire \& Challis, 2015). Vertical jump height $(\mathrm{VJH})$ is strongly related to the maximum strength of an athlete, whereas ground contact time $\left(\mathrm{T}_{\mathrm{c}}\right)$ characterizes dynamic explosive vertical jump capacity (Philips \& Flanagan, 2015; Thomas, Kyriakidou, Dos'Santos, \& Jones, 2017). Therefore the vertical jump development was assessed during repeated vertical jump test as VJH with further analysis of $\mathrm{T}_{c}$ in each sex and age category. Moreover, it was aimed to investigate the relationship between anthropometric parameters and $\mathrm{VJH}$.

\section{Methods}

\section{Participants' characteristics}

The presented cross-sectional study assessed 383 adolescent athletes, 203 females and 180 males from Czech and Slovak volleyball teams playing the 1st or 2nd national divisions. The ages of participants ranged from 13 to 19 years with the mean age of $16.0 \pm 1.6$. Written informed consent was obtained from all parents and/or responsible adults. The measurements were performed according to the ethical standards of Helsinki Declaration. The study protocol was approved by Ethics Committee of Faculty of Physical Education and Sports of Comenius University in Bratislava. Basic anthropometric measurements, including standing body height $(\mathrm{BH})$, body mass $(\mathrm{BM})$ were used to determine the body mass index (BMI) of each participant. $\mathrm{BM}(\mathrm{kg})$ was measured on an electronic scale to the nearest $0.1 \mathrm{~kg}$, with a scale of $150 \mathrm{~kg}$. Standing $\mathrm{BH}$ $(\mathrm{cm})$ was determined to the nearest $0.1 \mathrm{~cm}$ using a stadiometer. BMI was calculated using BM divided by $\mathrm{BH}$ squared $\left(\mathrm{kg} / \mathrm{m}^{2}\right)$.

\section{Vertical jump testing}

Participants of the study trained in various sport clubs spread across the Czech Republic and Slovak Republic, therefore we used an easily portable device, the FiTRO Jumper contact jump mat (FiTRONiC Diagnostic and Training Systems LTD, Bratislava, Slovakia) to assess $\mathrm{VJH}$. The population norms of physical fitness in nonathletic adolescents measured previously have used the same device for VJH assessment (Moravec, Kampmiller, \& Sedláček, 2002). The subjects performed a 10 seconds repeated vertical jump test. The starting position was a straddle standing with hands on hips 
in order to minimize the influence of the arms on the jump. After the initial hop, a 10 seconds repeated jump test was performed. During the jump, the trunk had to remain "as vertical as possible" to limit its influence on the performance and with the knees "as straight as possible" during the contact and flight phase (knee angle around 180 degrees, foot is in extension). The subjects performed 2 trials of the repeated jump test. If the participant jumped out of the jumping mat, the test was repeated. During both trials the subjects were instructed to jump "as high as possible". Rest intervals between trials were approximately 60 seconds. The average height and average $T_{c}$ of the three best attempts were taken into account for further analysis.

\section{Statistical analysis}

Descriptive statistics presented as means and standard deviations were calculated for male and female groups as a whole and sex-specific single year age groups. A Kolmogorov-Smirnov test ( $p=.367$ ) was used to test all data for normality and Levene's test $(p=.188)$ was used to test the homogeneity of variance. A two-way ANOVA design was applied to determine whether there were any significant main effects of age $(13,14,15,16$, 17,18 , or 19 years) or sex (female or male). Tukey's HSD post-hoc procedures were used to examine where significant effects occurred. Partial eta squared $\left(\eta_{\mathrm{p}}^{2}\right)$ was calculated as a measure of effect size. Value of .01 was considered as a small effect, .06 as a moderate effect and .14 above as a large effect. The association of $\mathrm{VJH}$ to anthropometric parameters was examined by using Pearson's correlation coefficient $r$. Correlation was considered as trivial $(r<.2)$, weak $(.2<r \leq .4)$, moderate $(.4<r \leq .6)$, strong $(.6<r \leq .8)$, and very strong $(.8<r \leq 1)$ (Hopkins, Marshall, Batterham, \& Hanin, 2009). All analyses were carried out using SAS (Version
9.2; SAS Institute, Cary, NC, USA) and Excel software (Version 2013; Microsoft, Redmond, WA, USA).

\section{Results}

\section{Participants' characteristics}

Anthropometric data of BM, BH, BMI in 203 female and 180 male adolescent volleyball players are presented in Table 1. Significant differences between females and males were found for BM $(p<.001)$ after 15 years of age and $\mathrm{BH}(p<.001)$ in all age categories. The BMI did not differ significantly between the female and male groups.

\section{Differences in VJH and $\mathrm{T}_{\mathrm{c}}$ in adolescent volleyball play- ers by sex and age}

Table 2 displays the $\mathrm{VJH}$ and $\mathrm{T}_{\mathrm{c}}$ data measured in adolescent volleyball players according to sex and age. ANOVA revealed that sex $(F(1,382)=108.08$, $\left.p<.001, \eta_{\mathrm{p}}^{2}=.068\right)$ and age $(F(6,376)=7.55, p<.001$, $\eta_{\mathrm{p}}^{2}=.03$ ) has a statistically significant effect on $\mathrm{VJH}$. The post hoc analysis showed that there were no significant sex differences until the age of 15 . From the age of 15 males perform significantly better than females $(p<.001)$ with moderate effect size. In males VJH increases continually with increasing age $(p<.001)$ with small effect size. There were no significant differences in $\mathrm{VJH}$ in females across all age categories.

Analysis of $\mathrm{T}_{\mathrm{c}}$ data revealed that only sex has significant effect on $\mathrm{T}_{c}(F(1,382)=5.26, p=.031$, $\eta_{\mathrm{p}}^{2}=.006$ ). The post hoc analysis showed that there were no significant sex differences until the age of 16 . From the age of 16 males perform significantly better than females $(p<.05)$ with small effect size. The analysis did not prove significant influence of age on $\mathrm{T}_{c}$ in either females or males $(F(6,376)=1.80, p=.074)$.

Table 1

The numbers of participants and anthropometric characteristics (presented as mean $\pm S D$ ) in adolescent volleyball players by sex and age

\begin{tabular}{|c|c|c|c|c|c|c|c|c|}
\hline \multirow[b]{2}{*}{ Age } & \multicolumn{2}{|c|}{$n$} & \multicolumn{2}{|c|}{ Body mass $(\mathrm{kg})$} & \multicolumn{2}{|c|}{ Body height (cm) } & \multicolumn{2}{|c|}{ Body mass index $\left(\mathrm{kg} / \mathrm{m}^{2}\right)$} \\
\hline & Female & Male & Female & Male & Female & Male & Female & Male \\
\hline 13 & 11 & 16 & $55.1 \pm 6.5$ & $54.8 \pm 9.3$ & $173.3 \pm 4.9$ & $168.5 \pm 7.0^{* *}$ & $18.5 \pm 1.8$ & $19.3 \pm 2.0$ \\
\hline 14 & 37 & 17 & $61.9 \pm 6.7$ & $69.5 \pm 9.8^{*}$ & $176.4 \pm 5.9$ & $183.9 \pm 7.3^{* *}$ & $19.8 \pm 1.6$ & $20.5 \pm 2.2$ \\
\hline 15 & 52 & 26 & $65.0 \pm 6.7$ & $72.9 \pm 7.1^{* *}$ & $177.8 \pm 4.7$ & $187.4 \pm 6.5^{* *}$ & $20.5 \pm 1.7$ & $20.7 \pm 1.6$ \\
\hline 16 & 26 & 47 & $68.8 \pm 6.5$ & $74.7 \pm 9.4^{* *}$ & $180.0 \pm 6.1$ & $188.1 \pm 8.2^{* *}$ & $21.2 \pm 1.4$ & $21.0 \pm 1.5$ \\
\hline 17 & 46 & 34 & $70.9 \pm 7.1$ & $77.8 \pm 7.5^{* *}$ & $179.7 \pm 5.3$ & $189.2 \pm 6.6^{* *}$ & $21.9 \pm 1.7$ & $21.7 \pm 1.6$ \\
\hline 18 & 20 & 19 & $72.3 \pm 7.8$ & $82.0 \pm 6.3 * *$ & $180.4 \pm 4.7$ & $191.5 \pm 4.5^{* *}$ & $22.2 \pm 2.1$ & $22.4 \pm 1.7$ \\
\hline 19 & 11 & 21 & $68.0 \pm 8.5$ & $84.2 \pm 5.5^{* *}$ & $178.2 \pm 4.8$ & $192.1 \pm 5.8 * *$ & $21.6 \pm 1.8$ & $22.8 \pm 1.0$ \\
\hline
\end{tabular}

Note. Asterisks indicate a statistically significant difference between females and males in the same age category $\left({ }^{*} p<.05,{ }^{* *} p<.001\right)$. 
Table 2

Vertical jump height (VJH) and ground contact time $\left(T_{c}\right)$ in adolescent volleyball players by sex and age. Values are presented as mean $\pm S D$.

\begin{tabular}{lccccc}
\hline & \multicolumn{2}{c}{ VJH $(\mathrm{cm})$} & & \multicolumn{2}{c}{$\mathrm{T}_{\mathrm{c}}(\mathrm{s})$} \\
\cline { 2 - 3 } \cline { 5 - 6 } Age & Female & Male & & Female & Male \\
\hline 13 & $30.4 \pm 2.7$ & $30.1 \pm 4.1$ & & $0.181 \pm 0.017$ & $0.179 \pm 0.027$ \\
14 & $32.2 \pm 4.9$ & $31.8 \pm 3.9$ & & $0.189 \pm 0.024$ & $0.185 \pm 0.024$ \\
15 & $32.1 \pm 3.4$ & $35.9 \pm 4.1^{* *}$ & & $0.182 \pm 0.020$ & $0.179 \pm 0.017$ \\
16 & $30.6 \pm 4.0$ & $37.2 \pm 4.8^{* * *}$ & & $0.190 \pm 0.025$ & $0.183 \pm 0.015^{*}$ \\
17 & $30.8 \pm 4.5$ & $39.4 \pm 4.3^{* * *}$ & & $0.194 \pm 0.020$ & $0.187 \pm 0.015^{*}$ \\
18 & $31.0 \pm 3.8$ & $40.1 \pm 4.9^{* * *}$ & & $0.196 \pm 0.023$ & $0.189 \pm 0.016^{*}$ \\
19 & $31.4 \pm 2.4$ & $41.3 \pm 5.8^{* * *}$ & & $0.195 \pm 0.025$ & $0.182 \pm 0.018^{* *}$ \\
\hline
\end{tabular}

Note. Asterisks indicate a statistically significant difference in post-hoc analysis between females and males in the same age category $\left({ }^{*} p<.05,{ }^{* *} p<.01,{ }^{* * *} p<.001\right)$.

\section{Relationship between anthropometric parameters and VJH in adolescent volleyball players}

From 14 years onward BM increased with age in both sexes. BH continuously increased with age in males whereas in females, $\mathrm{BH}$ reached its maximum at the age of 16 and remained stabilized. A correlation analysis between $\mathrm{BM}, \mathrm{BH}, \mathrm{BMI}$ and $\mathrm{VJH}$ revealed only trivial to weak sex-specific correlations in adolescent volleyball players. In females only weak negative correlation of VJH with BM ( $r=-.22, p=.043)$ was observed. In contrast in males, weak correlations of $\mathrm{VJH}$ with $\mathrm{BM}$ $(r=.28, p=.035)$, BH $(r=.24, p=.042)$ and BMI $(r=.28, p=.035)$ were identified.

\section{Discussion}

Considering the sex differences, after the age of 15 males performed better than the females in each age group. Furthermore, VJH in males was improved significantly with increasing age, while for females VJH reached a plateau at the age of 14 and then stagnated. Male volleyball players improved $\mathrm{VJH}$ with advancing age and accelerating gain was detected between 14-15 years of age. The sex differences and significantly better VJH scoring in males could be explained by the general increase in muscle mass connected with the increase of body height, which favored the males from the age of 14 years onwards (Laffaye, Choukou, Benguigui, \& Padulo, 2016; Lidor \& Ziv, 2010). Together with the morphological differences during maturation, mainly the increase of testosterone levels in males induces selective hypertrophy of type II muscle fibers influencing the explosive strength abilities (Metaxas et al, 2014). This result is consistent with earlier reports of jump performance depending on the muscle force in both athletic and non-athletic adolescents (Davis,
Briscoe, Markowski, Saville, \& Taylor, 2003). The difference in $\mathrm{VJH}$ between males and females is also related to the body fat percentage which is negatively associated to the jump height (Davis et al., 2003). Besides the overall lower VJH score than males, the female athletes reached their maximum at the age of 14, which was followed by stagnation or even the decline of VJP with increasing age. This trend in VJP was also observed in other studies of athletics as well as non-athletic adolescent populations (Ortega et al., 2011). A comparison of VJH between adolescent volleyball players and non-athletes in Slovak population (Moravec et al., 2002) revealed similar trends with regard to age and sex. However, in volleyball players, higher annual enhancement of VJH in each age category was observed comparing to non-athletes. The different sex related development of VJH across ages could be explained by the earlier termination of growth in females and divergent effect of estrogen and testosterone on skeletal muscle. The growth spurt in females occurs approximately 2 years earlier than in males and plateaus at 15-16 years of age, whereas males' growth spurts continue up to the age of 19-20 years (Tanner, Whitehouse, Marubini, \& Resele, 1976). Analysis of $\mathrm{T}_{\mathrm{c}}$ as an assessment of dynamic explosive vertical jump capacity revealed unchanged values across all age categories in females as well in males. However, the male players have significantly lower $T_{c}$ than females after 16 years of age.

In the context of anthropometric parameters, BM, $\mathrm{BH}$ and $\mathrm{BMI}$ increased with age in both male and female volleyball player groups. A significant sex difference was found for $\mathrm{BM}$ and $\mathrm{BH}$ between males and females in each age category after the age of 14. Surprisingly, there were no significant differences in BMI in any age category. A correlation analysis in volleyball players 
indicated only a weak negative correlation of BM with VJH in females, unlike in males, where weak correlations of BM, BH and BMI with $\mathrm{VJH}$ were observed. These results are in line with previously reported findings. A study of the relationship between VJH and BM revealed that VJH is independent on BM (Markovic \& Jaric, 2007). Similarly, BH showed no significant effect on vertical jump among sub-elite athletes (Aslan, Koç, Aslan, \& Özer, 2011). Davis et al. (2003) reported that the body fat percentage is negatively associated to the $\mathrm{VJH}$ and that there is no significant relationship between vertical jump and $\mathrm{BH}$ among recreational athletes. Although the above mentioned biological differences probably explain a large part of the pronounced sex and age differences, the much higher VJH scores of adolescent volleyball players than non-athletes reflect regular exercise training. The stagnation of $\mathrm{VJH}$ in female volleyball players after the age of 14 was not eliminated by regular exercise and may point to the differences in the training systems of male and female junior Czech and Slovak volleyball players. In male teams there is a strict chronological age differentiation. Training methods gradually and systematically develop fitness together with volleyball-specific skills. In contrast, female teams are age inconsistent and oriented on emphasizing game specific performance without adequate training to improve power and strength.

A limitation of our study was that we were not able to control the volume and intensity of strength training programs in volleyball teams.

\section{Conclusions}

The presented cross-sectional study of elite adolescent volleyball players showed that there were no significant sex differences in VJH between the elite male and female volleyball players until the age of 15 . From the age of 15 males jump significantly higher than females. In males VJH increases continually with increasing age however, in females no significant differences between all age categories were found. BM, BH and BMI did not significantly influence $\mathrm{VJH}$ in elite adolescent volleyball players.

Based on the expertise and knowledge of the system of long-term player development in the Slovak Republic and Czech Republic, a different trend of $\mathrm{VJH}$ in relation to age between the male and female volleyball players could be explained by natural physiological factors during growth and maturation.

\section{Acknowledgments}

This study was supported by the Agency of the Ministry of Education, Science, Research and Sport of the Slovak Republic under grants VEGA 1/0915/15 and VEGA 1/0548/18.

\section{Conflict of interest}

There were no conflicts of interest.

\section{References}

Aslan, C. S., Koç, H., Aslan, M., \& Özer, U. (2011). The effect of height on the anaerobic power of sub-elite athletes. World Applied Sciences Journal, 12, 208-211.

Davis, D. S., Briscoe, D. A., Markowski, C. T., Saville, S. E., \& Taylor, C. J. (2003). Physical characteristics that predict vertical jump performance in recreational male athletes. Physical Therapy in Sport, 4, 167-174.

Domire, Z. J., \& Challis, J. H. (2015). Maximum height and minimum time vertical jumping. Journal of Biomechanics, 48, 2865-2870.

Doré, E., Martin, R., Ratel, S., Duché, P., Bedu, M., \& Van Praagh, E. (2005). Gender differences in peak muscle performance during growth. International Journal of Sports Medicine, 26, 274-280.

Gallová, T., Doležajová, L., Lednický, A., Matulaitis, K., \& Bračič, M. (2015). The explosive power and speed abilities of lower extremities of young basketball players. Acta Facultatis Educationis Physicae Universitatis Comenianae, 55(2), 112-121.

Hopkins, W. G., Marshall, S. W., Batterham, A. M., \& Hanin J. (2009). Progressive statistics for studies in sports medicine and exercise science. Medicine \& Science in Sports \& Exercise, 46, 3-13.

Laffaye, G., Choukou, M. A., Benguigui, N., \& Padulo, J. (2016). Age- and gender-related development of stretch shortening cycle during a sub-maximal hopping task. Biology of Sport, 33, 29-35.

Lehnert, M., Psotta, R., Janura, M., Zemková, E., Malý, T., Hamar, D., ... Šebek, L. (2012). Anaerobic performance: Assessment and training. Olomouc, Czech Republic: Palacký University Olomouc.

Lidor, R., \& Ziv, G. (2010). Physical characteristics and physiological attributes of adolescent volleyball players - a review. Pediatric Exercise Science, 22, 114-134.

Malina, R. M. (1998). Growth and maturation of young athletes - is training for sport a factor? In K. M. Chan \& L. J. Micheli (Eds.), Sports and children (pp. 133-138). Hong Kong, People's Republic of China: Williams and Wilkins Asia-Pacific.

Markovic, G., \& Jaric, S. (2007). Is vertical jump height a body size-independent measure of muscle power? Journal of Sports Sciences, 25, 1355-1363.

Martin, R. J., Dore, E., Twisk, J., van Praagh, E., Hautier, C. A., \& Bedu, M. (2004). Longitudinal changes of maximal 
short-term peak power in girls and boys during growth. Medicine \& Science in Sports \& Exercise, 36, 498-503.

Matušov, M., Zapletalová, L., Duchoslav, L., \& Hagara, M. (2013). Relationship between the height of jump reach and the height of ball contact at spike in two different age categories of female volleyball players. Acta Facultatis Educationis Physicae Universitatis Comenianae, 53(2), 23-32.

Metaxas, T. I., Mandroukas, A., Vamvakoudis, E., Kotoglou, K., Ekblom, B., \& Mandroukas, K. (2014). Muscle fiber characteristics, satellite cells and soccer performance in young athletes. Journal of Sports Science and Medicine, 13, 493-501.

Moravec, R., Kampmiller, T., \& Sedláček, J. (2002). EUROFIT - physique and motor fitness of the Slovak school youth. Bratislava, Slovakia: Slovak Scientific Society for Physical Education and Sports, Ministry of Health of the Slovak Republic.

Naughton, G., Farpour-Lambert, N. J., Carlson, J., Bradney, M., \& Van Praagh, E. (2000). Physiological issues surrounding the performance of adolescent athletes. Sports Medicine, 30, 309-325.

Nikolaidis, P. T., Afonso, J., \& Busko, K. (2015). Differences in anthropometry, somatotype, body composition and physiological characteristics of female volleyball players by competition level: A cross-sectional study. Sport Sciences for Health, 11, 29-35.

Nikolaidis, P. T., Ziv, G., Arnon, M., \& Lidor, R. (2012). Physical characteristics and physiological attributes of female volleyball players - the need for individual data. Journal of Strength and Conditioning Research, 26, 2547-2557.

Ortega, F. B., Artero, E. G., Ruiz, J. R., España-Romero, V., Jiménez-Pavón, D., Vicente-Rodriguez, G., ... Sjöström, M. (2011). Physical fitness levels among European adolescents: The HELENA study. British Journal of Sports Medicine, 45, 20-29.

Philips, J. H., \& Flanagan, S. P. (2015). Effect of ankle joint contact angle and ground contact time on depth jump performance. Journal of Strength and Conditioning Research, 11, 3143-3148.

Roemmich, J. N., \& Rogol, A. D. (1995). Physiology of growth and development. Its relationship to performance in the young athlete. Clinics in Sports Medicine, 14, 483-502.
Sattler, T., Hadžić, V., Dervišević, E., \& Markovic, G. (2015). Vertical jump performance of professional male and female volleyball players: Effects of playing position and competition level. Journal of Strength and Conditioning Research, 29, 1486-1493.

Seger, J. Y., \& Thorstensson, A. (2000). Muscle strength and electromyogram in boys and girls followed through puberty. European Journal of Applied Physiology, 81, 54-61.

Sheppard, J. M., Cronin, J. B., Gabbett, T. J., McGuigan, M. R., Etxebarria, N., \& Newton, R. U. (2008). Relative importance of strength, power, and anthropometric measures to jump performance of elite volleyball players. Journal of Strength and Conditioning Research, 22, 758-765.

Sheppard, J. M., Gabbett, T. J., \& Stanganelli, L. C. (2009). An analysis of playing positions in elite men's volleyball: Considerations for competition demands and physiologic characteristics. Journal of Strength and Conditioning Research, 23, 1858-1866.

Sheppard, J. M., Nolan, E., \& Newton, R. U. (2012). Changes in strength and power qualities over two years in volleyball players transitioning from junior to senior national team. Journal of Strength and Conditioning Research, 26, 152-157.

Sumnik, Z., Matyskova, J., Hlavka, Z., Durdilova, L., Soucek, O., \& Zemkova, D. (2013). Reference data for jumping mechanography in healthy children and adolescents aged 6-18 years. Journal of Musculoskeletal and Neuronal Interactions, 13, 297-311.

Tanner, J. M., Whitehouse, R. H., Marubini, E., \& Resele, L. F. (1976). The adolescent growth spurt of boys and girls of the Harpenden growth study. Annals of Human Biology, 3, 109-126.

Taylor, M. J., Cohen, D., Voss, C., \& Sandercock, G. R. (2010). Vertical jumping and leg power normative data for English school children aged 10-15 years. Journal of Sports Sciences, 28, 867-872.

Thomas, C., Kyriakidou, I., Dos'Santos, T., \& Jones, P. A. (2017). Differences in vertical jump force-time characteristics between stronger and weaker adolescent basketball players. Sports, 5, 63.

Tonnessen, E., Svendsen, I. S., Olsen, I. C., Guttormsen, A., $\&$ Haugen, T. (2015). Performance development in adolescent track and field athletes according to age, sex and sport discipline. PLoS ONE, 10(6), e0129014. 